\title{
Implementasi Metode Reynolds menggunakan Simulasi Kerumunan Bebek
}

\author{
${ }^{1}$ Sidhiq Andriyanto, ${ }^{2} \mathrm{M}$. Suyanto, ${ }^{3}$ Sukoco \\ ${ }^{1,2,3}$ Pascasarjana Teknik Informatika Universitas AMIKOM Yogyakarta \\ ${ }^{1,2,3}$ Yogyakarta, Indonesia \\ Email : ${ }^{1}$ andriyanto.sidhiq@gmail.com, ${ }^{2}$ yanto@amikom.ac.id, ${ }^{3}$ pak_koco@yahoo.com
}

Abstract - "Simulasi Kerumunan Bebek Menggunakan Metode Reynolds" merupakan penelitian dengan tujuan untuk mengetahui perilaku kerumunan hewan bebek. Tujuan selanjutnya adalah untuk membuat simulasi kerumunan menggunakan metode Reynolds. Batasan variabel penelitian ini adalah obyek penelitian pada bebek Turi dewasa, metode yang digunakan adalah metode Reynolds. Simulasi dibuat menggunakan perangkat lunak Unity3D berbentuk 3D dan animasi yang diberikan hanya gerakan berjalan. Metode analisis penelitian ini adalah menggunakan metode research and development.

Hasil dari penelitian adalah data cara berjalan bebek dalam kerumunan untuk diterapkan dalam animasi 3D. Hasil akhir dari penelitian adalah simulasi kerumunan bebek yang berjalan pada bidang datar. Arah tujuan dipengaruhi oleh masukan mouse dan dapat menghindari rintangan ketika berjalan. Simulasi ini menggunakan aturan dasar Reynolds yakni cohesion, alignment dan separation.

Kesimpulan dari penelitian adalah terdapat kemiripan antara simulasi kerumunan dengan gerak berjalan kerumunan bebek aslinya dan metode Reynolds dapat diterapkan dalam simulasi kerumunan bebek dalam bentuk 3D. Penelitian menghasilkan animasi 3D kerumunan bebek yang diberikan kemampuan untuk menghindari rintangan dan target tujuan ditentukan oleh masukan mouse.

Keywords-Metode Reynolds, Kerumunan, Bebek, Berjalan

\section{PENDAHULUAN}

Saat ini, perkembangan teknologi komputer sangat tinggi. Penggunaan teknologi tersebut banyak diterapkan dalam film animasi 3D. Baik dalam pembuatan model karakter, animasi sampai proses akhir dalam pembuatan film secara keseluruhan. Karakter yang dibuat semakin kreatif dan menarik. Banyak film yang menceritakan tentang hewan yang memiliki sifat individu maupun berkelompok. Contoh film animasi hewan antara lain Life Pets, Chicken Little, Zootopia dan lainnya. Sedangkan untuk contoh film yang menggunakan karakter kerumunan hewan yaitu kerumunan kelelawar dalam film Batman Returns, kerumunan penguin di film Happy Feet, kerumunan semut di film Ant-Man, kerumunan Wildebeest dalam film The Lion King dan masih banyak lainnya [7]. 
Jurnal INTENSIF, Vol.1 No.2 Agustus 2017

ISSN: 2580-409X (Cetak) / 2549-6824 (Online)

Animasi tentang perilaku kerumunan pertama kali dibuat oleh Craig Reynolds pada tahun 1986 dengan nama Boid. Metode yang diciptakan Craig Reynolds ini terdiri dari seperangkat aturan sederhana yang akurat memodelkan perilaku kompleks dari sebuah kerumunan. Metode tersebut memiliki tiga macam aturan, yaitu ; pemisahan (separate), keselarasan (alignment), dan kohesi (cohesion) [10]. Separate merupakan kemampuan agen untuk menjaga jarak tertentu dengan agen lainnya agar tidak berbenturan. Alignment ialah kemampuan agen untuk menyelaraskan arah dan kecepatan gerak dengan agen yang lainnya. Cohesion adalah kemampuan agen untuk koheren (membentuk dan mendekati kelompok) dengan agen lainnya [18]. Craig Reynolds menerapkan metodenya pada sekawanan burung untuk gerakan kerumunan hewan tersebut. Metode Reynolds juga dipakai dalam penelitian-penelitian lain dan diterapkan pada kerumunan ikan, domba hingga manusia [19].

Perilaku hewan yang bergerak secara kerumunan tidak hanya dilakukan oleh burung dalam kehidupan nyata. Hewan lain yang masih termasuk golongan unggas juga bergerak secara kerumunan yaitu bebek. Perbedaan yang mendasar adalah bebek memiliki perilaku berjalan di atas tanah. Sedangkan burung sebagian besar perilakunya adalah terbang.

Simulasi kerumunan yang dibuat dengan karakter bebek yang berjalan di atas tanah dengan menggunakan metode Reynolds. Kerumunan tersebut diberikan titik tujuan atau arah target agar animator dapat mengendalikan kerumunan bebek sesuai keinginan animator atau sesuai storyboard yang ada. Pengukuran simulasi yang dibuat berdasarkan tingkat kemiripan gerakan kerumunan simulasi dengan gerakan kerumunan nyata.

Modeling Family Behaviors In Crowd Simulation [2] yaitu mensimulasikan kerumunan orang dalam sebuah keluarga dalam situasi evakuasi atau darurat. Metode yang digunakan adalah metode Reynolds dan Lubna mengembangkan model penentuan keputusan yang ditanamkan tiap agen agar bertindak sesuai dengan keadaan darurat yang dialami manusia. Lubna menyematkan sebuah algoritma keputusan kepada agen yang dapat mengakibatkan agen tertinggal dari kerumunan. Pada penelitian yang akan dilakukan, peneliti memberikan kemampuan setiap bebek untuk bergerak menuju titik tujuan meskipun bebek tertinggal dari kerumunan. Jika saat bebek berjalan menuju titik tujuan berada dalam radius kohesi, maka bebek yang tertinggal akan kembali masuk dalam kerumunan dan mengatur posisi (alignment).

Microscopic Crowd Simulation : Evaluation And Development Of Algorithms [15], David menguji beberapa algoritma yang diterapkan pada simulasi kerumunan. Dalam perbandingan tersebut, algoritma boid milik Reynolds memiliki kelebihan atas kemampuan agen dalam membentuk kelompok atau berkumpul kembali dalam kerumunan. Pengujian tersebut sangat berguna dalam mengembangkan penelitian berikutnya. Metode Reynolds diterapkan pada penelitian yang akan dilakukan berdasarkan sifat pergerakan jalan bebek dalam kerumunan yang solid dan tingkat keselarasan yang sangat baik. 
Jurnal INTENSIF, Vol.1 No.2 Agustus 2017

ISSN: 2580-409X (Cetak) / 2549-6824 (Online)

Biologically-Inspired Visual Simulation of Insect Swarms [15], membahas tentang kawanan serangga 3D yang terbang. Penelitian ini membandingkan metode Reynolds dengan metode yang mereka bangun. Hasil dari pengujian tersebut adalah serangga yang ditanamkan metode Reynolds memiliki kemampuan lebih baik dalam menghindari rintangan. Namun aturan keselarasan yang disematkan pada serangga tidak terlalu sesuai dengan pergerakan kawanan serangga yang nyata. Metode Reynolds sangat tepat untuk diterapkan pada kerumunan bebek yang memiliki tingkat kerapatan posisi yang lebih dekat dari serangga.

Penelitian Movement of the Tsunami Evacuation Simulation Using Boids and Pathfinding Algorithm menyajikan sebuah simulasi pergerakan manusia saat evakuasi pada bencana tsunami. Langkah awalnya adalah boid yang mewakilkan manusia tersebut diletakkan secara acak sebagai posisi awal. Kemudian boid diberi algoritma pathfinding untuk menemukan jalur dalam pergerakan tujuannya [9]. Penelitian yang akan dilakukan tidak menggunakan pathfinding.

Flocking Behaviour Simulation : Explanation and Enhancements in Boid Algorithm yang dilakukan oleh Mohit Sajwan dan rekannya membahas tentang pengujian terhadap metode Reynolds dan menyempurnakan algoritma yang dapat ditanamkan pada agen boid [8]. Untuk penelitian selanjutnya peneliti akan menerapkan prosedur atau algoritma yang sesuai dengan desain kemampuan bebek. Algoritma yang dapat diterapkan seperti pembatasan kecepatan terhadap pergerakan jalan bebek dan batasan area kerumunan dalam simulasi.

\section{METODE PENELITIAN}

Metode yang penulis gunakan dalam penelitian ini adalah metode Research And Development (R\&D). Metode penelitian dan pengembangan adalah metode penelitian yang digunakan untuk menghasilkan produk tertentu, dan menguji keefektifan produk tersebut [3] .

\section{HASIL DAN PEMBAHASAN}

Analisis gerakan bebek didapatkan dari hasil pengamatan langsung terhadap hewan bebek. Tujuan pengamatan tersebut untuk mengetahui pola pergerakan kaki dan tubuh pada saat berjalan. Pengamatan dilakukan dengan mengambil sample video (live shoot) pada hewan bebek. Peneliti melakukan pengambilan sudut gambar bebek tampak belakang dan samping agar pergerakan kaki dan tubuh bebek dapat terlihat dengan mudah.

Hasil yang didapat, bebek memiliki gerakan maju dan gerakan tubuhnya mengikuti tinggi rendah kaki saat mengangkat atau menginjak tanah. Pada penelitian ini, gerakan bebek yang peneliti ambil adalah gerakan berjalan maju. Pengamatan yang peneliti lakukan adalah pengamatan saat bebek berjalan pada bidang datar. Hasil pengambilan video dimasukkan dalam software pengolah video kemudian 
diekspor dalam bentuk file gambar berekstensi JPG. File gambar yang digunakan sebanyak satu kali perulangan masing-masing kaki (walk cycle).

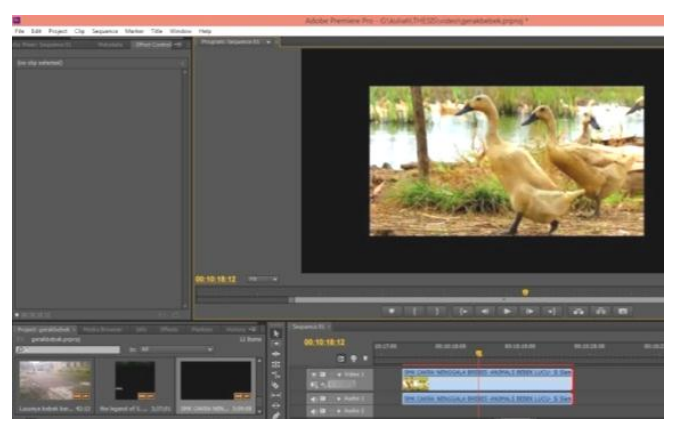

\section{Gambar 1. VIDEO BEBEK}

Tabel 1. AnALISIS JALAN BeBeK

\begin{tabular}{|c|c|c|}
\hline No & & Pergerakan \\
\hline 1 & & $\begin{array}{l}\text { Pergerakan maju } \\
\text { dengan kaki kiri di } \\
\text { depan dan kaki kanan } \\
\text { berada di belakang }\end{array}$ \\
\hline 5 & & $\begin{array}{l}\text { Pergerakan maju } \\
\text { dengan kaki kanan } \\
\text { terangkat berada di } \\
\text { belakang, kaki kiri } \\
\text { tegak lurus berada di } \\
\text { depan }\end{array}$ \\
\hline 9 & & $\begin{array}{l}\text { Pergerakan } \\
\text { dengan kaki kanan } \\
\text { berada di depan dan } \\
\text { telapak horizontal, } \\
\text { kaki kiri berada di } \\
\text { belakang }\end{array}$ \\
\hline 13 & & $\begin{array}{l}\text { Pergerakan maju } \\
\text { dengan tumit kiri } \\
\text { hampir menggantung, } \\
\text { kaki kanan berada di } \\
\text { depan hampir tegak } \\
\text { lurus }\end{array}$ \\
\hline 17 & & $\begin{array}{llr}\text { Pergerakan } & \text { maju } \\
\text { dengan kaki kanan } \\
\text { berada di depan dan } \\
\text { telapak } & \text { horizontal, } \\
\text { kaki kiri berada di } \\
\text { belakang }\end{array}$ \\
\hline
\end{tabular}

Analisis gerakan jalan bebek dalam kerumunan didapatkan dengan cara menggiring kerumunan bebek dan ketika memberikan pakan bebek. Tujuan adalah supaya bebek-bebek tersebut bergerak menuju ke arah yang diinginkan penggiring atau bergerak menuju tempat makanan berada. 
Tabel 2. ANALISIS KERUMUNAN BEBEK

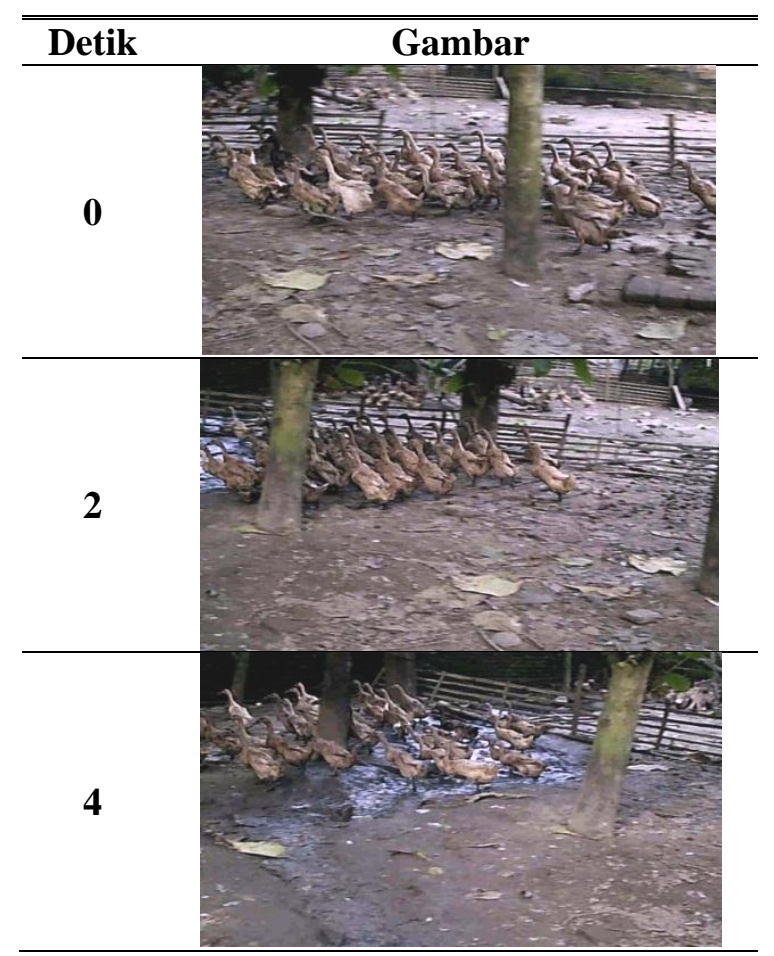

Tabel 3. AnALisis JALAN BEBEK

\begin{tabular}{|c|c|}
\hline Gambar & Sudut \\
\hline & $\begin{array}{lr}\text { Model } & \text { Badan } \\
\text { Bebek } & \text { Tampak } \\
\text { Depan } & \end{array}$ \\
\hline & $\begin{array}{lr}\text { Model } & \text { Badan } \\
\text { Bebek } & \text { Dan Paruh } \\
\text { Bebek } & \text { Tampak } \\
\text { Atas } & \end{array}$ \\
\hline & $\begin{array}{lr}\text { Model } & \text { Badan } \\
\text { Bebek } & \text { Tampak } \\
\text { Samping } & \end{array}$ \\
\hline & $\begin{array}{l}\text { Model Kaki Bebek } \\
\text { Tampak Atas }\end{array}$ \\
\hline
\end{tabular}


Peneliti memberikan susunan nama pada struktur antara sendi gerak yang disesuaikan dengan struktur anatomi tubuh bebek. Pembuatan struktur sendi gerak berdasarkan hasil analisis ruas sendi.

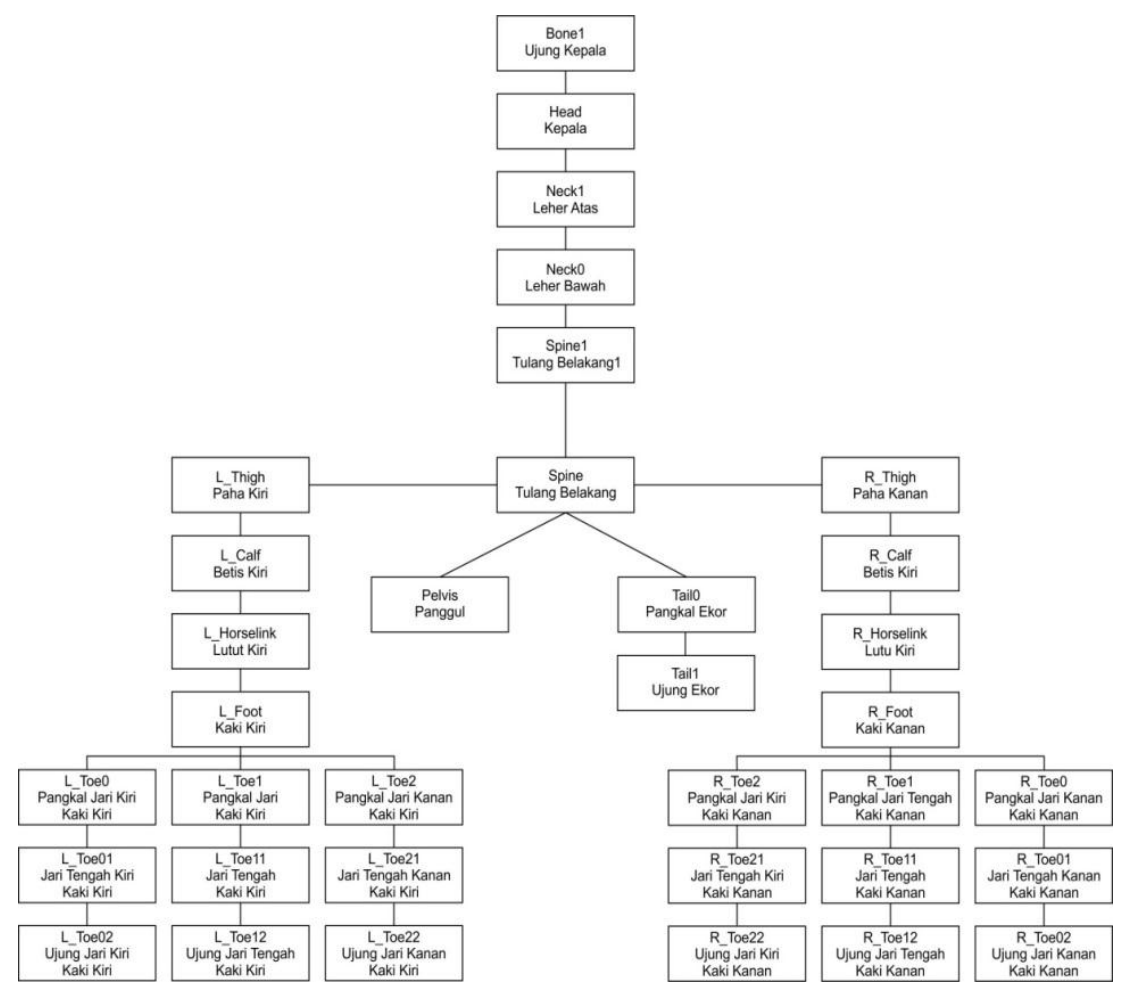

Gambar 2. STRUKTUR SENDi GERAK PADA MODEL BEBEK

- Pembuatan Karakter 3D

Peneliti menggunakan Cube Modelling dalam pembuatan model karakter hewan bebek. Foto bebek (blueprint) dipakai sebagai acuan pembuatan model tersebut. Blueprint hewan bebek diambil dari tiga foto yang berbeda sudut pengambilan gambarnya.

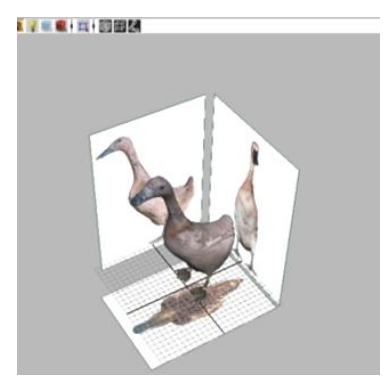

\section{Gambar 3. StRUKTUR SENDi GeraK PADA MODEL BebeK}

- Rigging Karakter

Rigging merupakan proses pembuatan tulang pada model 3D. Proses ini termasuk dalam tahapan pembuatan sebuah model karakter terlihat hidup dengan pergerakan yang diberikan. 


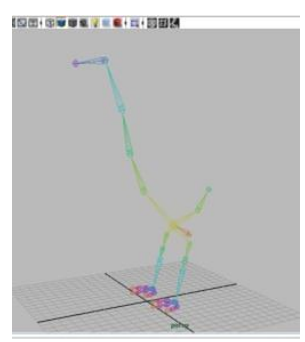

Gambar 4. STRUKTUR BONE PADA MODEL 3D

Rincian struktur hubungan antar tulang pada model bebek dapat dilihat pada gambar 9 dan 10.

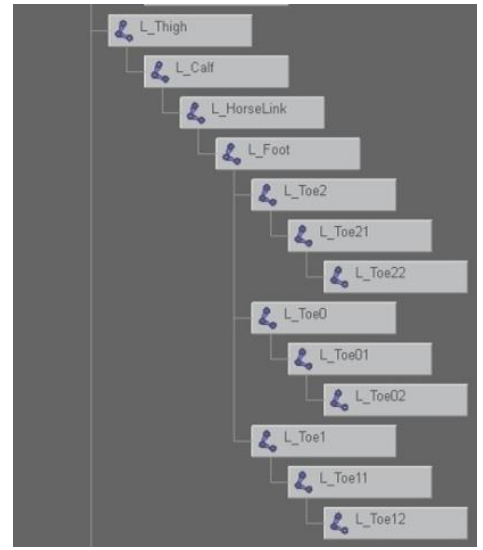

Gambar 5. RINCIAN SRUKTUR BONE MODEL 3D KAKI KIRI

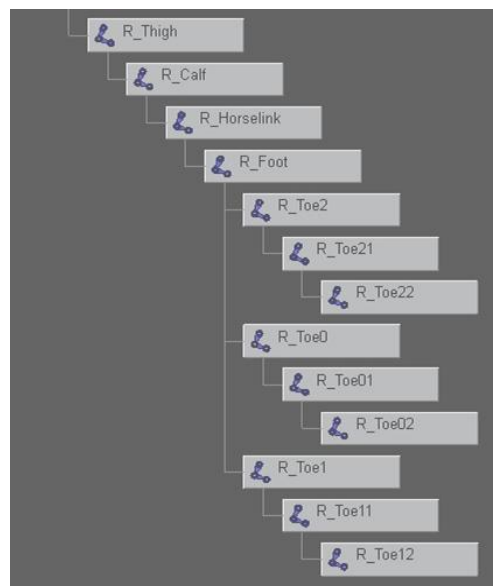

Gambar 6. RINCIAN STRUKTUR BONE MODEL 3D KAKI KANAN

- Pembuatan Animasi Langkah

Animasi yang dibuat adalah gerak langkah (walk cycle). Dalam proses pengerjaan animasi langkah ini menggunakan metode frame by frame. Perpindahan kaki dilakukan dengan mengatur posisi tulang pada model bebek yang mengacu pada gerakan bebek aslinya. 


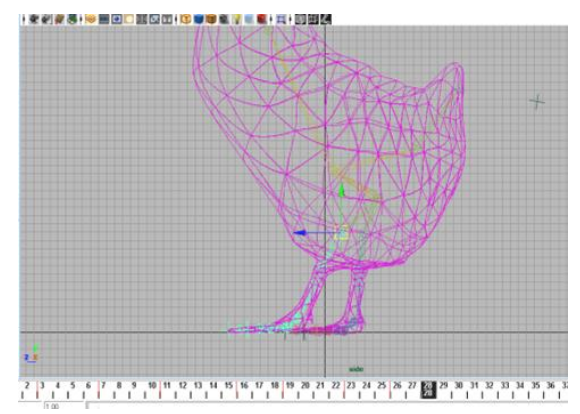

\section{Gambar 7. ANIMASI WALK CyCLE BeBEK}

- Implementasi Klip Animasi

Klip Animasi pada penelitian ini menggunakan animasi jalan yang telah dibuat sebelumnya. Animasi jalan tersebut adalah pergerakan langkah bebek.

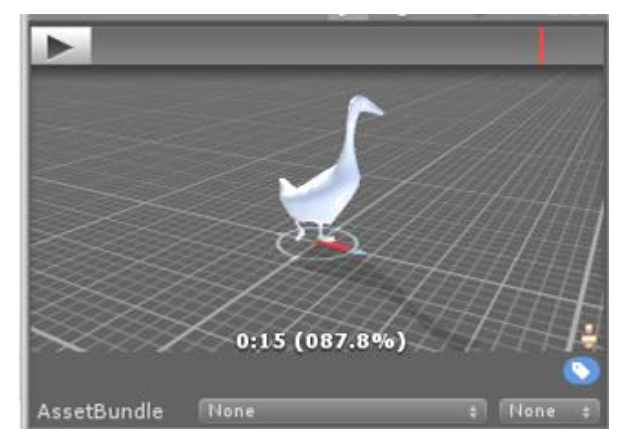

\section{Gambar 8. KLIP ANIMASI WALK CYCLE BEBEK}

Animator controller merupakan fasilitas Unity3D yang berguna untuk mengontrol fase animasi jalan dan dipasang pada model bebek.

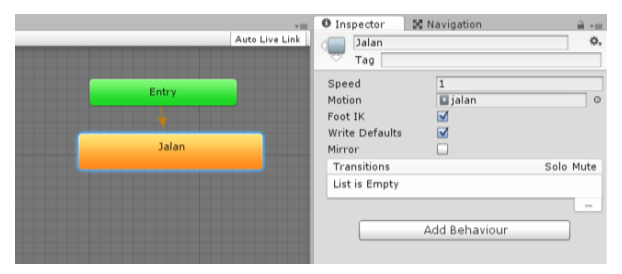

\section{Gambar 9. ANIMATOR CONTROLLER JALAN BEBEK}

- $\quad$ Penerapan Metode Reynolds

Penerapan aturan kohesi (cohesion) ini diawali dengan langkah awal yaitu sebuah kondisi untuk mengetahui posisi dari bebek. NeighborRadius adalah jarak minimal antara bebek satu dengan lainnya. Fungsi Steer digunakan untuk menentukan titik langkah berikutnya agar bebek mendekat dengan bebek lain. CohesionWeight berisi nilai masukan berupa besarnya daya tarikan untuk mendekati bebek terdekat. 


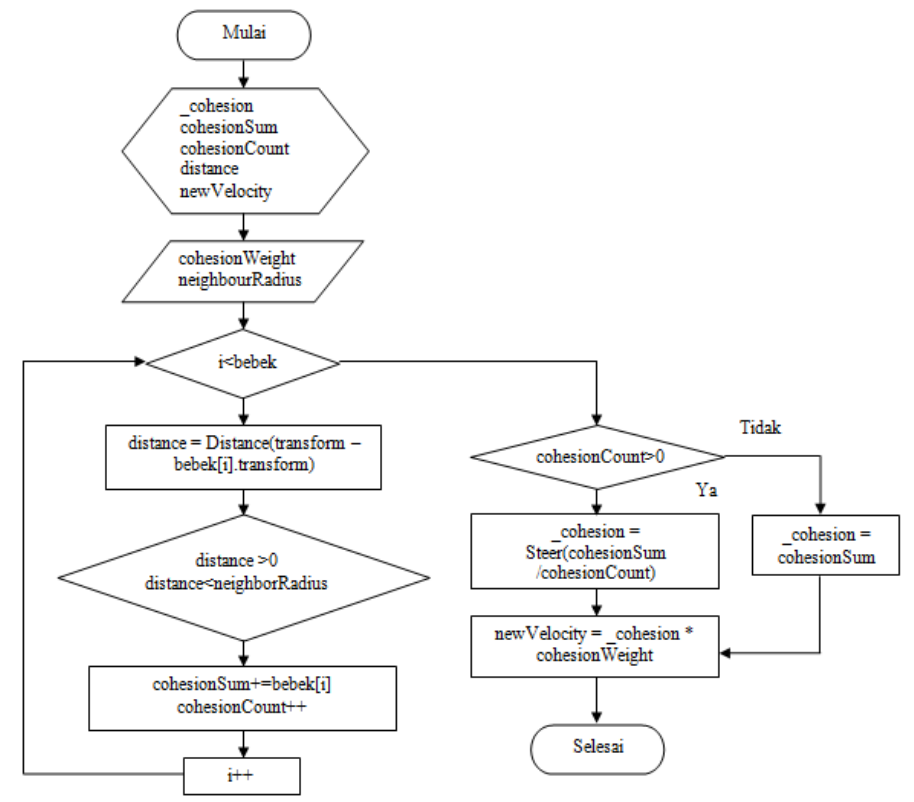

Gambar 10. FLOWCHART KOHESI (COHESION)

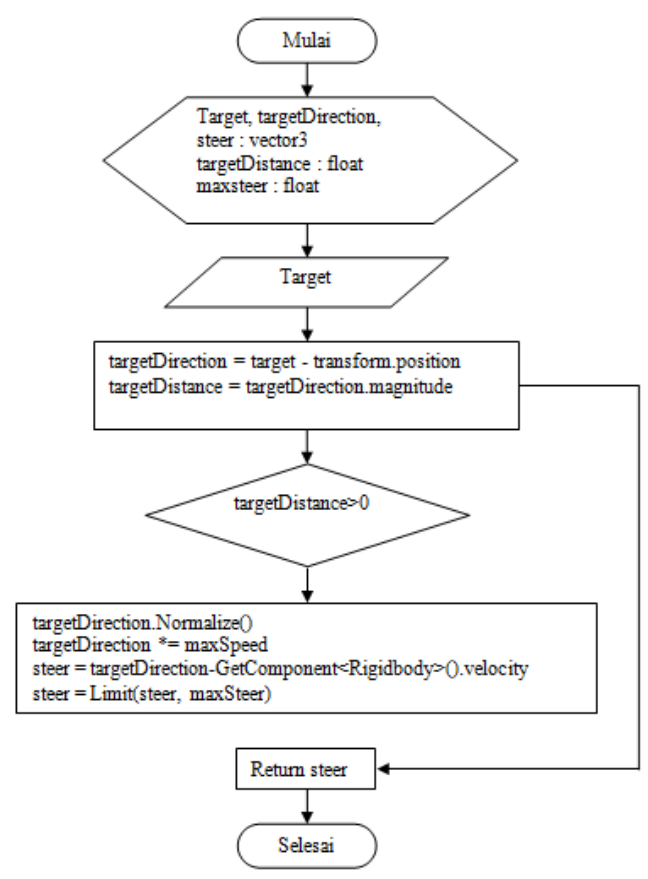

Gambar 11. FLOWCHART STEER

Fungsi Steer adalah untuk menetapkan langkah yang akan ditempuh selanjutnya. Kemudian membuat bebek bergerak menuju titik tersebut. Kecepatan bebek dalam bergerak dibatasi dalam fungsi Limit. 


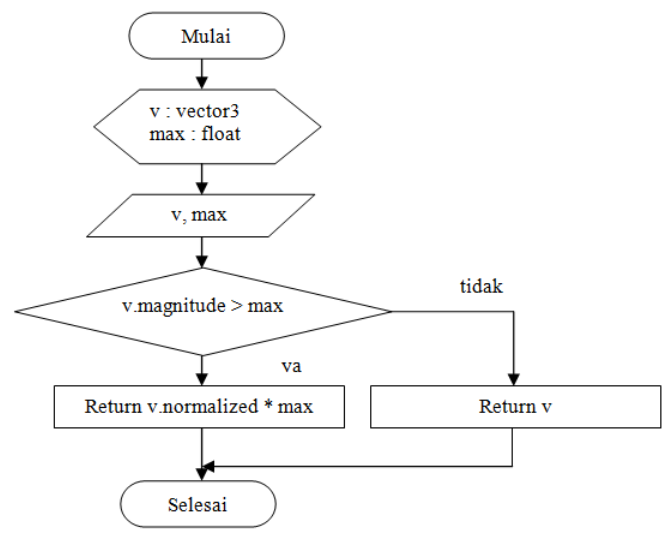

Gambar 12. FLOWCHART LIMIT

Fungsi Limit digunakan untuk mengatur kecepatan gerakan bebek. Dalam aturan keselarasan (alignment), langkah pertama adalah pemberian sebuah kondisi untuk mengetahui posisi dari bebek dengan batasan neighborRadius. Jika jarak bebek dengan bebek lainnya lebih dekat dari neighborRadius. Maka, bebek mengurangi kecepatannya dengan Limit. Jika jarak antara bebek satu dengan bebek lainnya lebih jauh, maka bebek menambah kecepatannya agar seimbang dengan yang lainnya.

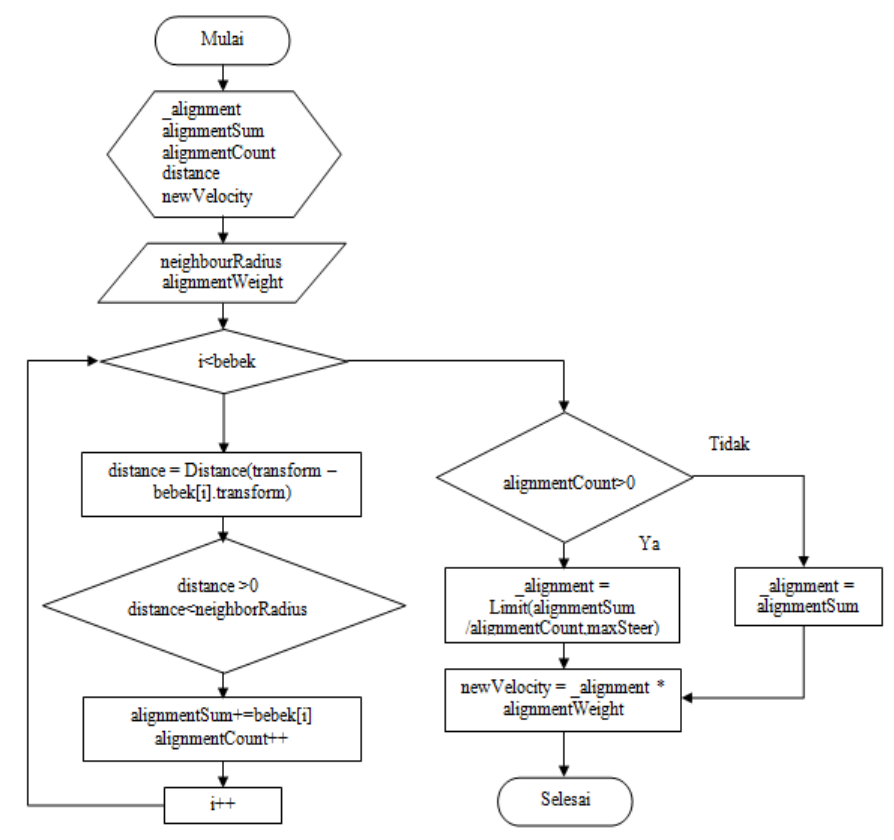

Gambar 13. FLOWCHART STEER

\section{a. Aturan Pemisahan (Separation)}

Langkah awal aturan ini adalah mengukur jarak antara bebek dengan bebek lain. DesiredSeparation menyimpan nilai keinginan untuk memisahkan diri dan digunakan sebagai rujukan kekuatan pemisah. Direction akan membuat bebek bergerak menuju titik tujuan. Nilai dari newVelocity berisi perkalian dari _separation dengan separationWeight. Tujuannya adalah untuk memperbesar nilai pemisahan. Sehingga bebek akan terus menjauh dari kerumunan. 


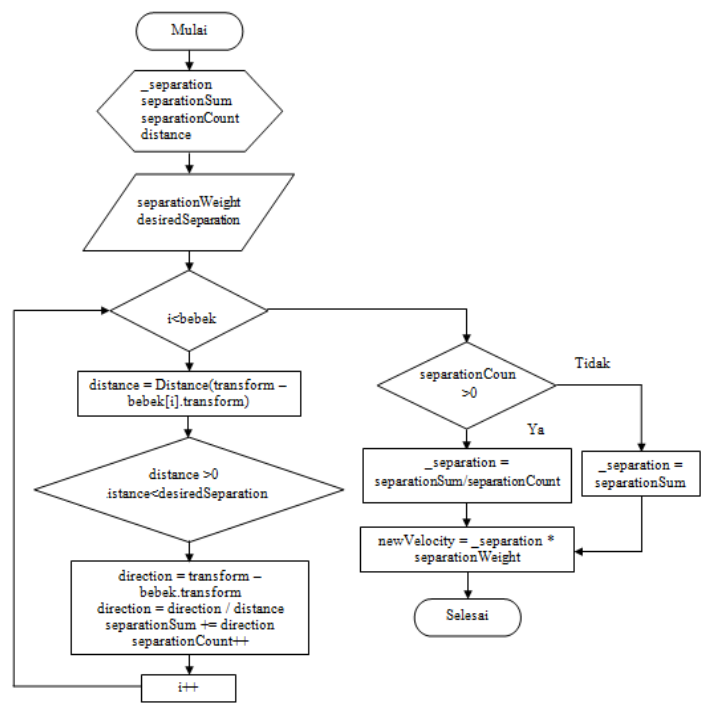

\section{Gambar 14. FLOWCHART PEMISAHAN (SEPARATION)}

- Penyempurnaan Model Gerakan

Penyempurnaan model gerakan bertujuan untuk memperbaiki kesalahan pada setup rigging, klip animasi, gerakan kerumunan dan pemberian rintangan.

NavMesh merupakan struktur data yang menggambarkan permukaan tempat berjalan dan memungkinkan digunakan untuk menemukan jalur dari satu lokasi ke lokasi lain. Fitur ini digunakan agar bebek menghindari rintangan dengan gerakan lebih baik.

- NavMesh Baking

Proses ini adalah membuat sebuah permukaan tempat berjalan.

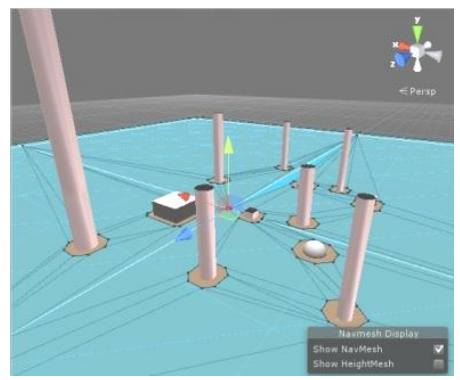

Gambar 15. TAMPILAN NAVMESH BAKING

- $\quad$ Navmesh Agent

Komponen NavMesh Agent diberikan pada bebek agar dapat mengenali rintangan di permukaan jalan. 


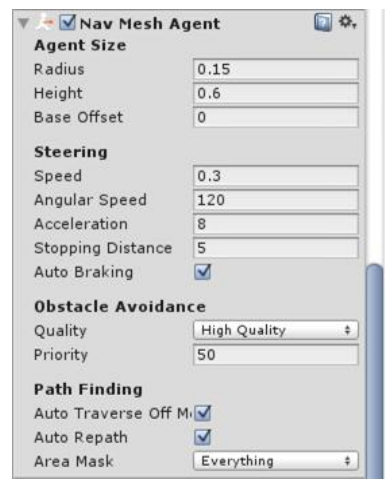

\section{Gambar 16. PENGATURAn NAVMESh AGENT}

Radius digunakan untuk memperhitungkan benturan antara rintangan dan agen lainnya. Height merupakan tinggi badan agen yang ukurannya lebih rendah dari rintangan. Speed adalah kecepatan maksimal pergerakan bebek.

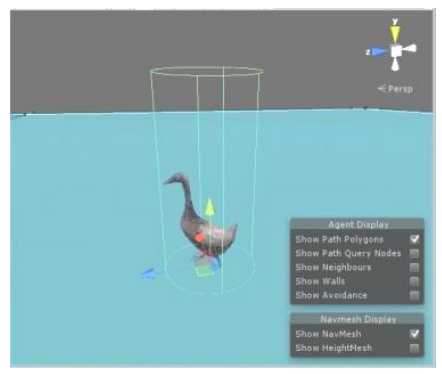

Gambar 17. TAMPILAN NAVMESH AGENT

- $\quad$ NavMesh Obstacles

NavMesh Obstacles adalah komponen yang digunakan untuk menggambarkan hambatan yang harus dihindari oleh agen.

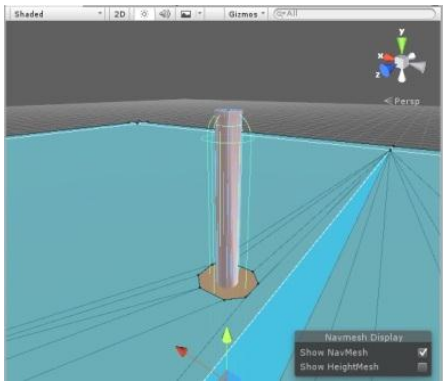

\section{Gambar 18. TAMPILAN NAVMESH OBSTACLES}

\section{- Implementasi Simulasi Kerumunan Bebek}

Tahap berikutnya adalah implementasi gerakan kerumunan bebek yang diberi target tujuan. Alur simulasi ini digambarkan dalam bentuk bagan flowchart ketika bebek diberikan input target tujuan. 


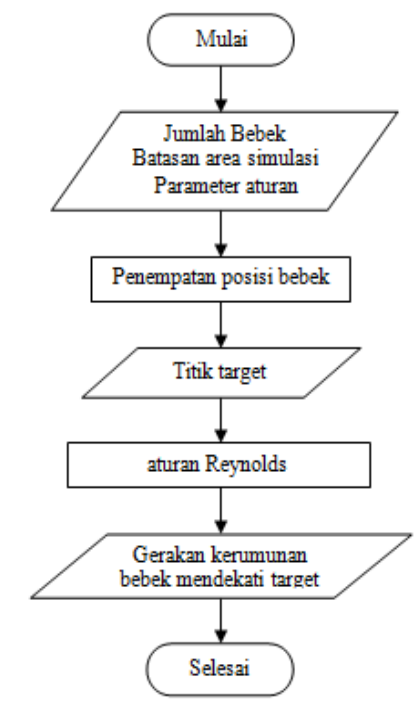

\section{Gambar 19. FlOWCHART SIMULASI KERUMUNAN BEBEK}

\section{- Pemberian Target Tujuan}

Skrip TargetJalan adalah untuk mengubah posisi Sphere secara realtime melalui masukan klik mouse. Simulasi ini menggunakan obyek Sphere berwarna merah sebagai tanda target tujuan bebek.

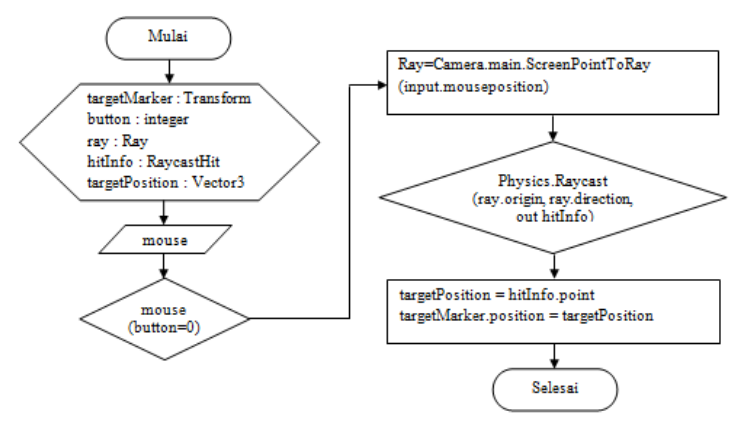

\section{Gambar 20. FlOWCHART SiMULASI KERUMUNAN BEBEK}

Tahap berikutnya adalah mencari target Sphere dengan tag "Player". Fungsi LookAt() untuk membuat tubuh bebek menghadap arah titik posisi Sphere. Proses berikutnya adalah memberikan fungsi bergerak menuju titik Sphere berada dengan kecepatan yang normal dengan transform.Translate. Alur prosesnya digambarkan dalam flowchart Target Tujuan. 


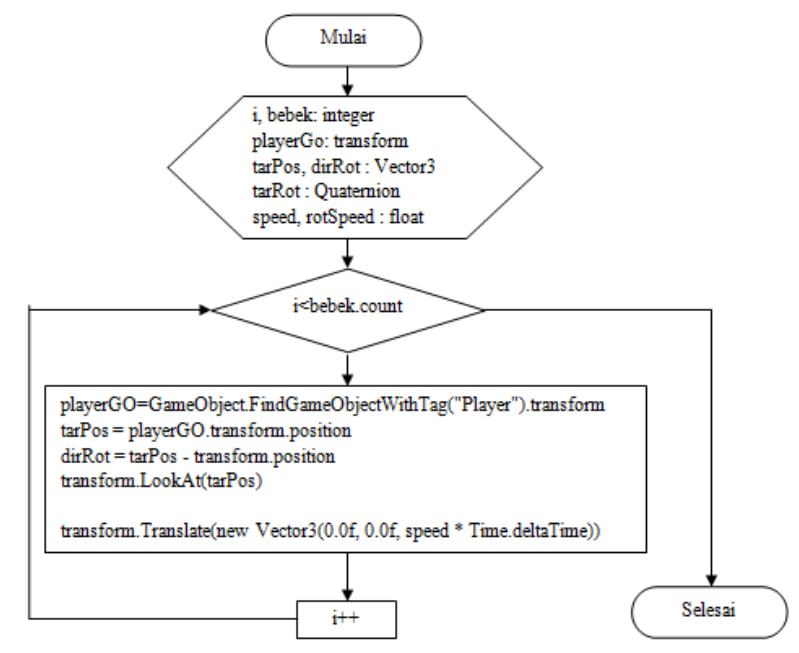

Gambar 21. FlOWCHART TARGET TUJUAN

\section{- Hasil Implementasi Simulasi Kerumunan Bebek}

Simulasi dimulai dengan penempatan bebek secara acak. Penempatan ini berada di dalam sebuah batasan yang telah diatur sebelumnya. Kemudian semua bebek bergerak menuju titik target. Pada saat menuju target, bebek akan mendekati bebek lainnya. Aturan yang berlaku saat itu adalah aturan kohesi (cohesion). Setelah mendekati bebek lainnya maka membentuk kelompok dengan jarak dan kecepatan berjalan yang seimbang. Aturan yang berlaku adalah aturan keselarasan (alignment). Ketika kerumunan bebek melewati rintangan (obstacle), bebek akan memecah atau menjauhi bebek di sampingnya. Aturan yang berlaku saat itu adalah aturan pemisahan (separation). Setelah melewati rintangan, maka bebek akan tertarik kembali karena aturan kohesi dan menyeimbangkan jarak serta kecepatannya dalam kerumunan karena aturan keselarasan.
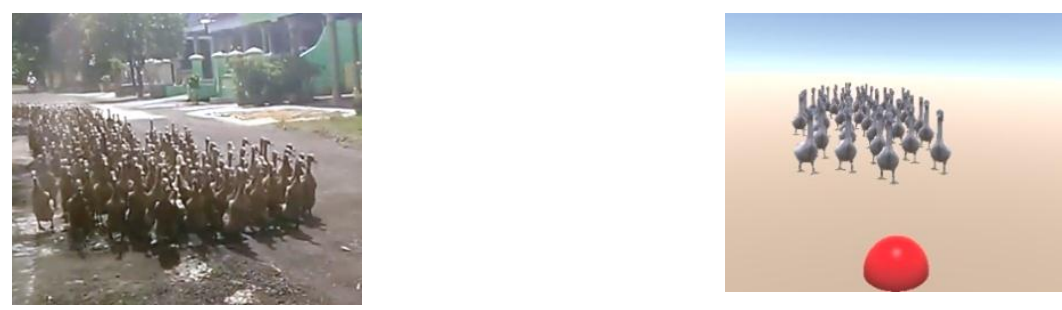

Gambar 22. KERUMUNAN BEBEK BERJALAN
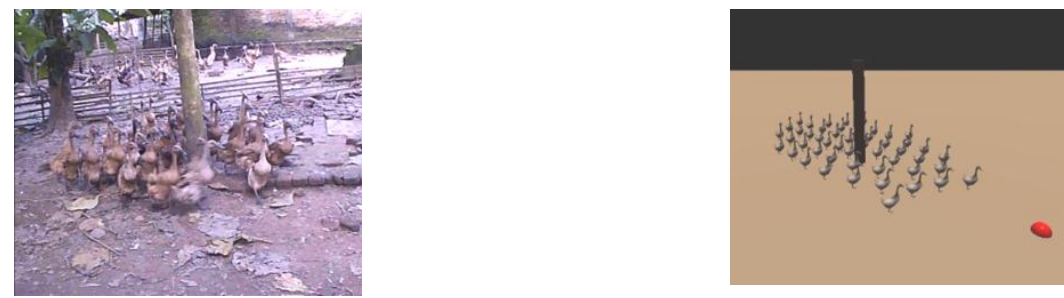

Gambar 23. KERUMUNAN BEBEK MENGHINDARI RINTANGAN 


\section{- Analisis Hasil}

Pengujian simulasi dilakukan dengan cara mengajukan beberapa pertanyaan kepada 10 orang responden. Dalam penelitian ini, pertanyaan diajukan berkaitan tentang tingkat kemiripan simulasi, perilaku menghindari rintangan (obstacles), metode yang digunakan dan struktur sendi gerak pada karakter bebek. Pertanyaan yang diajukan yaitu sebagai berikut :

- Bagaimana struktur penulangan dan persendian pada karakter bebek

- Bagaimana arah target gerakan yang diberikan melalui input mouse

- Bagaimana tingkat kemiripan simulasi dalam gerakan kerumunan yang nyata

- Bagaimana pendapat anda tentang simulasi kerumunan bebek menggunakan metode Reynolds

- Bagaimana perilaku bebek menghindari rintangan (obstacles).

Dari pertanyaan tersebut peneliti memasukkan pada tabel di bawah ini :

Tabel 4. TABEL PENILAIAN RESPONDEN

\begin{tabular}{|c|c|c|c|c|c|c|c|c|c|c|c|c|c|c|c|c|c|c|c|c|c|}
\hline \multirow{4}{*}{ No } & \multirow{4}{*}{ Responden } & \multicolumn{20}{|c|}{ Jawaban } \\
\hline & & \multicolumn{4}{|c|}{ Pertanyaan 1} & \multicolumn{4}{|c|}{ Pertanyaan 2} & \multicolumn{4}{|c|}{ Pertanyaan 3} & \multicolumn{4}{|c|}{ Pertanyaan 4} & \multicolumn{4}{|c|}{ Pertanyaan: } \\
\hline & & $\mathrm{s}$ & st & $\mathrm{K}$ & $\mathrm{T}$ & $\mathrm{s}$ & $\mathrm{s}$ & $\mathrm{K}$ & $\mathrm{T}$ & $\mathrm{s}$ & & $\mathrm{K}$ & $\mathrm{T}$ & $\mathrm{S}$ & $\mathrm{c}$ & & $\mathrm{T}$ & $\mathrm{S}$ & & $\mathrm{K}$ & $\mathrm{T}$ \\
\hline & & $\mathrm{s}$ & $\mathrm{s}$ & $\mathrm{s}$ & $\mathrm{s}$ & $\mathrm{s}$ & $\mathrm{s}$ & $\mathrm{s}$ & $\mathrm{s}$ & $\mathrm{s}$ & $\mathrm{s}$ & $\mathrm{s}$ & $\mathrm{s}$ & $\mathrm{s}$ & $\mathrm{s}$ & $\mathrm{s}$ & $\mathrm{s}$ & $\mathrm{s}$ & $\mathrm{s}$ & $\mathrm{s}$ & $\mathrm{S}$ \\
\hline 1 & Responden 1 & $\checkmark$ & & & & $\checkmark$ & & & & & $\sqrt{v}$ & & & $\checkmark$ & & & & & $\sqrt{7}$ & & \\
\hline 2 & Responden 2 & & $\sqrt{ }$ & & & $\checkmark$ & & & & & $\sqrt{v}$ & & & $\checkmark$ & & & & $\checkmark$ & & & \\
\hline 3 & Responden 3 & $\checkmark$ & & & & & $\sqrt{ }$ & & & & $\sqrt{ }$ & & & & $\checkmark$ & & & $\checkmark$ & & & \\
\hline 4 & Responden 4 & & $\sqrt{v}$ & & & $\checkmark$ & & & & $\checkmark$ & & & & $\checkmark$ & & & & & $\sqrt{v}$ & & \\
\hline 5 & Responden 5 & $\checkmark$ & & & & $\checkmark$ & & & & & $\sqrt{v}$ & & & & $\checkmark$ & & & & $\checkmark$ & & \\
\hline 6 & Responden 6 & & $\sqrt{ }$ & & & & $\checkmark$ & & & & $v$ & & & & $\checkmark$ & & & & $\checkmark$ & & \\
\hline 7 & Responden 7 & $\checkmark$ & & & & & $\sqrt{v}$ & & & & $\sqrt{ }$ & & & & $\nabla$ & & & $\checkmark$ & & & \\
\hline & & & & & & & & & & & & & & & & & & & & & \\
\hline 8 & Responden 8 & & $\sqrt{v}$ & & & $\checkmark$ & & & & & $\sqrt{v}$ & & & $\checkmark$ & & & & & $\checkmark$ & & \\
\hline 9 & Responden 9 & & $\sqrt{v}$ & & & & $\sqrt{v}$ & & & & $\bar{v}$ & & & $\checkmark$ & & & & & $\checkmark$ & & \\
\hline \multirow[t]{2}{*}{10} & Responden 10 & & $\sqrt{v}$ & & & $\checkmark$ & & & & & $\sqrt{v}$ & & & $\checkmark$ & & & & & $\checkmark$ & & \\
\hline & JUMLAH & 4 & 6 & & & 6 & 4 & & & 1 & 9 & & & 6 & 4 & & & 3 & 7 & & \\
\hline
\end{tabular}

Dari pertanyaan yang diajukan kepada responden, peneliti mengambil kesimpulan penilaian sebagai berikut :

- Struktur penulangan dan persendian karakter sudah sesuai dengan anatomi bebek

- Target yang diberikan melalui input mouse sudah sesuai

- Tingkat kemiripan pada simulasi ini sesuai dengan gerakan realistis

- Penerapan metode Reynolds pada kerumunan bebek sudah sesuai

Perilaku bebek dalam menghindari rintangan sesuai dengan aslinya. 
Jurnal INTENSIF, Vol.1 No.2 Agustus 2017

ISSN: 2580-409X (Cetak) / 2549-6824 (Online)

\section{KESIMPULAN DAN SARAN}

Kesimpulan dari penelitian ini adalah perilaku kerumunan bebek dalam simulasi yang dibuat memiliki kemiripan dengan gerak berjalan kerumunan bebek aslinya. Selain itu untuk membuat simulasi kerumunan bebek menggunakan metode Reynolds dapat dilakukan dengan tahapan sebagai berikut ; membuat karakter bebek, memberikan animation klip berjalan, memberikan tiga aturan dasar Reynolds, memberikan arah target berjalan dengan input mouse. Saran untuk penelitian berikutnya adalah struktur penulangan bebek untuk sayap ditambahkan guna pemberian klip animasi mengepakkan sayap, pemberian gerakan berbelok yang baik, penambahan klip animasi seperti berhenti, gerakan makan, mengepakkan sayap dan model bebek yang dibuat bervariasi dari ukuran tubuh, warna, postur tubuh.

\section{DAfTar Pustaka}

[1] Z. G. Djalle, The Making of 3D Animation Movie. Bandung: Informatika, 2006.

[2] Eliyan and L. Fayez, "Modeling Family Behaviors In Crowd Simulation," Qatar University, 2017.

[3] L. Famukhit, Muga, M. Suyanto, and Sukoco, "Simulasi Gerak Kepiting Menggunakan Metode Inverse Kinematics,” J. Speed - Sentra Penelit. Eng. dan Edukasi, vol. 8, no. 2, 2016.

[4] S. Haryati, "Research And Development (R\&D) Sebagai Salah Satu Model Penelitian Dalam Bidang Pendidikan. Ilmiah Dinamika," vol. 37, no. 1, 2012.

[5] Hasan and M. Iqbal, Pokok-Pokok Materi : Teori Pengambilan Keputusan. Jakarta: Ghalia Indonesia, 2002.

[6] Kusumaningtyas and Pratiwi, Potensi Bisnis dan Kisah Suskes Praktisi. Jakarta: Agriflo, 2012.

[7] W. Li, D. Wolinski, J. Pettré, and Ming C Lin, "Biologically-Inspired Visual Simulation of Insect Swarms," Comput. Graph. Forum c Eurographics Assoc. John Wiley Sons Ltd, vol. 34, no. 2, 2015.

[8] Mudhana, I. M. P., Purnomo, M. H., Nugroho, and S. M. S, "Movement of the Tsunami Evacuation Simulation Using Boids and Pathfinding Algorithm," in Seminar Nasional ReTII 9, 2014, pp. 198-204.

[9] C. W. Reynolds, "Boids : Flocking Behaviors For Autonomous Characters," 2016. .

[10] Reynolds and W. Craig, "Boids: Background and Update," 2016. [Online]. Available: http://www.red3d.com/cwr/boids/.

[11] R. Roedavan, UNITY : Tutorial Game Engine. Bandung: Informatika, 2016.

[12] M. Sajwan and S. S. Devashish Gosain, "Flocking Behaviour Simulation : Explanation and Enhancements in Boid Algorithm,” Int. J. Comput. Sci. Inf. Technol., vol. 5, no. 4, 2014. 
[13] S. Sarmady, "Modeling And Simulation Of Movement And Behaviors In Large Crowd Using Cellular Automata," Universiti Sains Malaysia, 2008.

[14] S. Sopiyana, A. R. Setioko, and M.E. Yusnandar, "Identifikasi Sifat-Sifat Kualitatif Dan Ukuran Tubuh Pada Itik Tegal, Itik Magelang, Dan Itik Damiaking," in Pros. Lokakarya Nasional Inovasi Teknologi Dalam Mendukung Usaha Ternak Berdaya Saing, 2006.

[15] D. Thalmann and S. Musse, Crowd Simulation. London: Springer-Verlag, 2007.

[16] R. C. W, Flock, Herds, and Schools, "A Distributed Behavioral Model," in Proceeding of SIGGRAPH, 2004.

[17] S. Wojowasito, Kamus Umum Lengkap. Bandung, 1997.

[18] D. Wolinski, "Microscopic Crowd Simulation: Evaluation And Development Of Algorithms. Data Structures and Algorithms," Universit'e Rennes, 2016.

[19] Zulkarnain and I. Abdurrozaq, "Simulasi Efek Tembakan Pada Manusia," STMIK AMIKOM Yogyakarta, 2017. 